\title{
Emigração internacional de brasileiros para os Estados Unidos: as redes sociais e o papel de intermediação nos deslocamentos exercido pelas agências de turismo*
}

\author{
Dimitri Fazito** \\ Eduardo Luiz Gonçalves Rios-Neto***
}

\begin{abstract}
Este trabalho tem como objetivo principal descrever o papel dos "mecanismos intermediários" (em especial o papel ativo das agências de turismo) no processo de emigração internacional de brasileiros para os EUA. Ao propor uma perspectiva relacional para o entendimento do fenômeno migratório, procedeuse a uma análise estrutural formal (fundamentada na Análise de Redes Sociais e Teoria dos Grafos) que possibilitasse a compreensão da emigração por meio de suas propriedades estruturais básicas. As agências de turismo ocupam importante posição estrutural de intermediação das travessias dos emigrantes, desempenhando papel preponderante na regulação dos fluxos migratórios através das redes sociais estabelecidas no sistema da migração internacional brasileira.
\end{abstract}

Palavras-chave: Emigração internacional. Redes sociais. Intermediação. Análise estrutural. Agências de turismo. Modelo de Grafos.

\section{Introdução}

A abordagem processual e sistêmica dos fenômenos migratórios se tornou bastante difundida entre os pesquisadores a partir da década de 70. Conceitualmente, os sistemas migratórios se compõem, em linhas gerais, de unidades territoriais específicas interligadas (origem, trajeto e destino), de fluxos de pessoas e objetos e de um sentido organizacional geral que deve garantir coerência e integridade a todos os componentes do sistema (KRITZ et al., 1992; MASSEY et al., 1998).
Mais recentemente, a partir da década de 80 , a abordagem processual contribuiu para a consolidação da idéia de que o sistema migratório internacional fosse entendido como uma "rede de países ligados por interações migratórias, cuja dinâmica é amplamente condicionada pela operação de uma variedade de redes que conectam atores migrantes em diferentes níveis de agregação" (KRITZ; ZLOTNIK, 1992, p. 15).

Dessa forma, novas contribuições teóricas e metodológicas foram feitas no sentido de operacionalizar e aprofundar a perspectiva sistêmica das migrações - espe-

\footnotetext{
* Os autores agradecem o apoio das agências de fomento CNPq e Capes, e também os pareceristas pelos comentários críticos e sugestões pertinentes.

** Pesquisador visitante da Universidade da Flórida (EUA), doutor em Demografia pelo Cedeplar/UFMG.

*** Doutor em Demografia e professor titular de Demografia do Cedeplar/UFMG.
} 
cialmente o caso das teorias sobre redes e capital social, teorias dos sistemas mundiais e a teoria da causalidade cumulativa (PORTES, 1995; BOYD, 1989; FAWCETT, 1989; SASSEN, 1995; MASSEY et al., 1998).

Este estudo propõe uma alternativa para a abordagem sistêmica das migrações que permita, ao mesmo tempo, uma compreensão relacional e dinâmica dos deslocamentos, bem como a operacionalização das análises, através de um "modelo estrutural das migrações".

O modelo estrutural aqui proposto utiliza recursos analíticos da Teoria dos Grafos (ORE, 1963; HARARY, 1969; DIESTEL, 2000) e da Análise de Redes Sociais (WASSERMAN; FAUST, 1994; HARARY; WHITE, 2001; SCOTT, 2000; WATTS, 1999; BARABASI, 2003), ${ }^{1}$ permitindo, assim, a representação objetiva dos sistemas de migração orientada por uma lógica formal rigorosa, sem, contudo, impedir a compreensão intuitiva e precisa das relações implicadas.

Em linhas gerais, o modelo estrutural baseado na Análise de Redes (incluindo a Análise de Redes Sociais) focaliza as "relações" (conexões, linhas, laços) entre "pontos" (vértices, moléculas, terminais de computadores, pessoas, unidades espaciais, etc.) num espaço qualquer - não necessariamente euclidiano, como pode ser pensado o "espaço social". O ponto de partida de qualquer análise de redes (e não apenas social), segundo Barabasi (2003), consiste na identificação de pontos e relações e, fundamentalmente, na análise de seus padrões de distribuição em um determinado sistema. Em outras palavras, do ponto de vista da Análise de Redes, a distribuição de apenas dois parâmetros (pontos e relações) que compõem um dado sistema deve determinar estruturalmente a dinâmica e evolução das configurações iniciais, bem como a complexidade e emergência de inovações (inclusive de novas relações). E mais: independentemente do conteúdo das relações e dos atributos individuais dos pontos, deve existir em cada sistema especificado - por sua distribuição-padrão - uma configuração estrutural invariante (a chamada topologia) passivel de formalização.

Assim, a partir de um modelo de redes, o analista é capaz de determinar uma topologia concreta em um dado sistema (social, por exemplo) e identificar as "regularidades" que o orientam. A Análise de Redes é eminentemente sistêmica, não apenas pelo reconhecimento dos padrões estruturais das relações, mas também pela focalização da dinâmica e complexidade esboçadas nas diferentes distribuições de relações e pontos de um sistema específico. E, além da dinâmica relacional considerada pela Análise de Redes, assume-se por princípio que todo e qualquer sistema de relações observa regularidades estruturais, independentemente de quem ou o que as observa, pensa ou sofre (BARABASI, 2003; WATTS, 2004).

Agora, imagine o leitor a cadeia ecológica alimentar, um sistema de transporte aéreo, a rede virtual da Internet, a rede de células nervosas, a rede de agentes financeiros e de indivíduos no mercado, ou uma rede de relações de apoio social para idosos em uma pequena comunidade. Estudos contemporâneos baseados na Análise de Redes têm mostrado que todos esses sistemas se auto-organizam como uma "rede de relações" que pode ser identificada formalmente (NEWMAN, 2003). O mais interessante, como mostra Barabasi (2003), é que muitos desses sistemas, independente de seu conteúdo, podem ser entendidos através de modelos semelhantes. Até o momento, foram elaborados três modelos de redes elementares (e suas variações) para todo e qualquer tipo de sistema de relações: modelos de "redes aleatórias" (random networks); modelos de "redes de mundo pequeno" (small world networks); e modelos de "redes de escala livre" (scale free networks), além da família dos chamados modelos híbridos (hibrid networks). Embora a maior parte das pesquisas feitas

\footnotetext{
${ }^{1}$ A Teoria dos Grafos constitui um ramo especial da matemática discreta moderna (ORE, 1963; GORBATOV, 1988; MANBER, 1989), ao passo que a Análise de Redes Sociais é também reconhecida como uma perspectiva teórico-metodológica estruturalista das Ciências Sociais (KNOKE; KUKLINSKY, 1983; DEGENNE; FORSÉ, 1999; SCOTT, 2000; WELLMAN, 2002).
} 
em Ciências Sociais trate, em geral, as redes sociais como modelos de "mundo pequeno" (WATTS, 2004), ainda não há consenso sobre o tema, mesmo porque a recente "descoberta" dos modelos de escala livre traz novas perspectivas bastante atraentes para a análise de redes sociais.

Finalmente, como estudo de caso, aplicou-se o modelo estrutural das redes ao sistema de migração internacional brasileiro (especificamente à emigração para os Estados Unidos), na tentativa de compreender, formalmente, o papel desempenhado pelos "mecanismos intermediários" (agentes e agências de turismo) nos processos migratórios desse sistema.

\section{Procedimentos metodológicos}

A vantagem em estudar as migrações numa perspectiva sistêmica diz respeito às possibilidades de formalização e compreensão do processo e dinâmica da causalidade nos fenômenos migratórios. Em outras palavras, a noção de sistema recuperada por Kritz e Zlotnik (1992) visa a representação adequada dos processos empíricos por meio de modelos objetivos mais abrangentes, que identifiquem as relações de causalidade sem perder a dimensão objetiva de mensuração dos efeitos concretos.

Portanto, o modelo dos sistemas de migração é uma representação possível do fenômeno empírico observado. Mas, além deste truísmo, deve-se agregar o fato de que a análise sistêmica rigorosa está baseada nos chamados modelos matemáticos de grafos operacionalizados pela Análise de Redes propriamente dita (Network Analysis).

Segundo Barabasi (2003), qualquer análise sistêmica, pautada na avaliação das relações (vínculos) entre pontos (atores) quaisquer e independentes de seu contexto, configura em essência um modelo (ou uma representação) estrutural de redes, cujos fundamentos, por definição, estão estabelecidos na Teoria dos Grafos e suas leis. ${ }^{2}$

A formalização de um sistema empírico de migração em modelo estrutural particular deve observar critérios objetivos e pode seguir três estratégias metodológicas distintas de modelagem: Modelo de Redes Totais (Full Network Model, em Soares, 2002a); Modelo de Redes Egocentradas (Egocentered Network Model, em McCarty, 2001); e Modelo de Grafos (Graph Model, em Fazito, 2005).

Tecnicamente, o modelo de Redes Totais é uma estratégia possível quando se tem acesso às relações entre todos os vértices/nós constituintes de um sistema empírico. Em se tratando do estudo das migrações, deve-se tomar cuidado ainda com a dimensão de abordagem do sistema: se mais ou menos abstrata. Soares (2002a), por exemplo, analisou a dinâmica migratória das microrregiões de Governador Valadares e Ipatinga em comparação ao resto do Brasil, considerando as relações (de reciprocidade) entre todas as microrregiões do país. Dessa forma, as microrregiões operaram como nós da rede e as trocas migratórias (ou seja, os fluxos de migrantes) foram tratados como vínculos ou laços apropriados ao sistema migratório. Nesse caso, o sistema de migração expressa uma rede de fluxos completa e fechada. ${ }^{3}$

Num outro exemplo, Fígoli e Fazito (2006) apresentam a análise da rede total de um grupo de 220 indígenas do Alto Rio Negro durante o processo de migração para Manaus, ocorrido no final dos anos 70 . Nessa situação, as informações coletadas

\footnotetext{
${ }^{2}$ Como sugere ainda Barabasi (2003), qualquer sistema dado - seja a rede virtual da Internet, a malha urbana, a cadeia alimentar em dado ecossistema, as redes neurais e atômicas ou as redes sociais no mercado econômico, por exemplo - possui uma topologia (ou estrutura invariável e permanente), que depende exclusivamente de apenas dois parâmetros (vértices/nós e arcos/laços). Cada topologia exerce constrangimento estrutural que, em princípio, independe do contexto empírico de atuação do sistema, pois observa as leis topológicas elementares.

3 Importante salientar que, nesse caso, o fluxo de pessoas como o resultado do agregado de migrantes de uma para outra região não é o mesmo que uma rede social strictu sensu. Esta diz respeito exclusivamente às relações sociais entre as pessoas de um determinado contexto de interação. Assim, na dimensão operacionalizada por Soares (2002a), a "rede de fluxos" é, de fato, uma rede migratória elementar subjacente à rede social da migração, composta pelas pessoas e suas relações sociais cotidianas.
} 
pelo etnógrafo permitiram a configuração da rede social total de uma comunidade indígena específica (Tukano) que vivenciou o processo de deslocamento espacial - os indígenas são os nós da rede, enquanto suas relações de amizade, parentesco, trabalho e outras constituem os laços que compõem essa rede.

O modelo de Redes Egocentradas é uma estratégia possível quando não se dispõe de informações sobre todos os nós e laços de um sistema. Nesse caso, adota-se uma perspectiva micro, centrada na visão particular de um nó ou ator da rede (Ego). Em trabalho recente, Fazito e Soares (2008), utilizando a proposta metodológica desenvolvida por Chris McCarty (2002), analisam 50 redes pessoais de valadarenses retornados dos EUA. Ali, cada indivíduo relata sua experiência migratória e enumera os vínculos estabelecidos com outros indivíduos durante o processo da migração internacional. Assim, os autores conseguiram identificar a topologia (distribuição de nós e laços) das redes de migrantes internacionais que entraram regular e irregularmente nos EUA, partindo de uma perspectiva pessoal, centrada na percepção cognitiva do informante sobre o mundo social no qual se inserem seus contatos pessoais.

Finalmente, o modelo de Grafos é uma estratégia apropriada somente para a análise exploratória do sistema empírico de migração que, no entanto, possibilita a identificação objetiva das redes migratórias que compõem um sistema em sua totalidade.

Em linhas gerais, pode-se dizer que um sistema de migração se define pela associação e sobreposição de diferentes "redes migratórias": especificamente, "redes de fluxos" e "redes sociais". Enquanto a rede de fluxos representa a estrutura topológica bruta e abstrata de um sistema, a rede social compreende a topologia sensível e correspondente ao contexto histórico-social do qual faz parte. Enfim, em se tratando de um sistema de migração, embora as redes de fluxos e social se configurem a partir de pessoas (nós) e suas relações, deve-se pensar em dimensões analíticas diversas, mas complementares. A rede de fluxos refere-se ao agregado estatístico da população de indivíduos que se deslocam entre duas regiões distintas (é o simples somatório dos deslocados que representam os vínculos entre duas regiões tomadas como nós da rede). Já a rede social diz respeito não ao agregado, mas sim à estrutura social composta pelas relações sociais cotidianas entre as diversas pessoas, migrantes e nãomigrantes, de uma dada comunidade.

O modelo de Grafos (FAZITO, 2005) exemplifica uma estratégia analítica exploratória para a representação compacta do sistema de migração, pois, por meio de uma formalização rigorosa, estabelece a abstração dimensional das redes migratórias e integra, em uma só perspectiva, as redes de fluxos e sociais de todo o processo. Diferentemente dos modelos anteriores, aqui o nível de abstração é maior e tem como objetivo fundamental identificar uma topologia geral, capaz de apontar posições e relações estruturais preponderantes na configuração do sistema empírico de migração.

Nesse tipo de modelagem, os vértices/ nós da rede não devem ser confundidos com atores sociais concretos (regiões ou pessoas), pois indicam, de fato, "posições" ocupadas ou latentes dentro dos sistemas empíricos. Os vínculos (arcos/laços) entre as posições correspondem às relações estruturais possíveis ou prováveis segundo a natureza do sistema. Este trabalho se concentra sobre os fundamentos e desdobramentos dessa modelagem para os estudos de migração, analisados aqui por um estudo de caso (FAZITO, 2005).

Inicialmente, foram selecionados textos da literatura acadêmica sobre a emigração de brasileiros para os EUA que tratassem dos seguintes temas: intermediários, agentes e trajetórias dos migrantes; redes sociais e redes migratórias; reunificação familiar; remessas; retornados; e capital social nas comunidades de imigrantes internacionais.

Note-se que os temas selecionados privilegiam a dinâmica dos sistemas de migração e procuram salientar as interações e relações entre os diversos componentes de um sistema de migração - origem, destino, comunidades de migrantes e não-migrantes, agentes intermediários na travessia, objetos e representações do espaço de interme- 
diação (FAZITO, 2005). Assim, o primeiro passo consistiu na determinação das possíveis posições constitutivas desse sistema empírico de migração.

Por exemplo, todos os membros familiares, em geral, ocupam uma mesma posição estrutural ${ }^{4}$ nas redes pessoais de um emigrante, pois, afinal, são todos seus parentes. Contudo, pode ocorrer de membros de uma mesma família serem migrantes retornados e, desse modo, ocuparem outra posição estrutural concorrente na intermediação - porque, além de serem parentes que podem auxiliar em uma travessia, são também migrantes retornados, que possuem conhecimento especializado e têm contatos exclusivos que potencializam a travessia do emigrante. Assim, esses indivíduos retornados devem ser representados por vértices (significando posições) diferentes dos membros familiares.

Em uma situação ideal, se fosse possível desagregar as diferentes posições estruturais ocupadas no mesmo sistema por cada indivíduo, poder-se-ia identificar com precisão o perfil de cada intermediário (de fato, de todo e qualquer ator na rede) e verificar sua força relativa, o capital social do ator e sua posição no sistema. Vale lembrar que a formalização alcançada neste trabalho impede a compreensão das singularidades de cada ator isoladamente e, por conseqüência, impossibilita o entendimento, de forma adequada, das relações entre cada posição, perfil do ator intermediário e padrão concreto dos fluxos migratórios - esta modelagem propõe apenas uma análise exploratória do sistema e sua topologia geral.

$\mathrm{Na}$ leitura, análise e interpretação de cada texto utilizado, as conexões, laços ou relações entre cada posição estrutural ocupada foram caracterizados de acordo com a descrição particular e, posteriormente, formalizados como arcos entre os vértices.
Adotou-se como critério básico para a definição dos arcos o sentido direcionado do "repasse" de migrantes. Isto é, fez-se a pergunta: "Quem passa o migrante para quem?/Através de quem o migrante realiza sua travessia?" Desse modo, utilizou-se como critério para a direção dos arcos apenas a capacidade de "fazer circular os migrantes". Os problemas desse procedimento são maiores naqueles estudos de caso em que o foco de análise principal não eram os intermediários e não se encontra uma descrição detalhada das trajetórias dos migrantes, gerando dados incompletos sobre as posições latentes e ocupadas pelos atores e suas relações no processo migratório.

Assim, a partir da abstração de estudos de caso constituídos, as redes de migração foram elaboradas - facultando a determinação das medidas e índices utilizados neste estudo -, fundamentadas nas análises elementares dos Grafos e, principalmente, nas análises de redes sociais. Os índices de densidade, coesão e intermediação fundamentam-se em algoritmos matemáticos específicos, que buscam avaliar formalmente a natureza, o teor, a qualidade e o volume das relações entre posições e atores de uma rede (sistema). Portanto, os mesmos procedimentos técnicos para estabelecimento das medidas nas análises de redes sociais foram utilizados aqui. ${ }^{5}$

Deve-se ainda ressaltar que a perspectiva sistêmica aqui adotada, devido à limitação técnica e ao constrangimento dos dados coletados, é fundamentalmente uma análise sincrônica. A imposição desse tipo de perspectiva obrigou a "chapar" redes que se desenvolveram ao longo do tempo, criando problemas de interpretação a serem devidamente avaliados mais adiante.

É evidente a ausência de estudos sistemáticos e comparativos sobre os mecanismos intermediários dos sistemas

\footnotetext{
${ }^{4}$ A posição estrutural exerce constrangimento sobre os indivíduos, porém, não é fixa ou alheia ao contexto das relações concretas entre atores, papéis e posições ocupadas. Isto é, as posições estruturais também podem sofrer o constrangimento das ações individuais e coletivas - por exemplo, se a experiência dos retornados no exterior tende ao fracasso constante, dificilmente teriam força suficiente para "disputar" uma posição estrutural favorável à intermediação.

5 Para uma análise detalhada de cada medida, ver, especialmente, Wasserman e Faust (1994) e o manual de referência do software de análise de redes sociais (estatística) UCINET 6 (BORGATTI et al., 2002).
} 
de migração internacional (cf. GOSS; LINDQUIST, 1995; CASTLES; MILLER, 2003; KRISSMAN, 2005). Talvez a flagrante exceção seja o trabalho pioneiro de Faist (2000), ao mostrar que as redes operam como "meso-estruturas", intermediando o deslocamento de migrantes entre origem e destino. Assim, "ao fornecer uma 'mesoestrutura', a proposta conceitual persegue uma análise relacional sistemática do processo migratório e pós-migratório no nível meso. Essa análise concebe os migrantes potenciais inseridos e constituídos em suas interações, relacionalmente" (FAIST, 2000, p. 59$) .6$

No caso da literatura brasileira sobre as migrações, a situação se mostra ainda mais crítica e, com exceção de alguns poucos trabalhos sobre a imigração italiana em fins do século XIX e início do XX (HUTTER, 1972, 1986; BRIGANTTI, 1996), não foram encontrados estudos que focalizassem, particularmente, os agentes de intermediação dos deslocamentos.

Desse modo, foram necessários critérios específicos de seleção do material pesquisado e, posteriormente, uma estratégia alternativa de análise comparativa para replicação do modelo estrutural utilizado na análise de outros 16 estudos de caso (FAZITO, 2005, cap. 4).

A reconstituição de parte do sistema de migração internacional do Brasil, isto é, a emigração de brasileiros para os EUA nos últimos 25 anos (e sua formalização através dos grafos), se deu a partir das informações descritivas sobre as relações entre migrantes (emigrantes e imigrantes), membros da comunidade de origem e destino, instituições e trajetos de deslocamento.

Devido à escassez de publicações específicas sobre os intermediários e as trajetórias migratórias propriamente ditas, concluiu-se que seria melhor, após rigorosa comparação do material coletado, reunir todos os estudos e informações adicionais em um único caso generalizado. Portanto, aqui os estudos de caso conformam, na realidade, um grande mosaico em que as informações sobre os atores e suas relações se complementam a partir de fontes variadas.

\section{O sistema de migração internacional de brasileiros para os EUA}

A particularidade histórica recente dos deslocamentos no Brasil, segundo Brito (1995, p. 29), deve-se à reestruturação produtiva do sistema capitalista global que, atualmente, promove o movimento inverso das populações, em relação à Segunda Revolução Industrial na segunda metade do século XIX. Contemporaneamente, a tendência observada dos fluxos populacionais internacionais vai dos países periféricos (como o Brasil) para as nações centrais do sistema capitalista. E, desse modo, o Brasil tem-se tornado, nos últimos 20 ou 30 anos, um país de emigrantes internacionais, que buscam, na mobilidade espacial para os países capitalistas centrais, encontrar também a sonhada mobilidade social (BRITO, 1995; PATARRA; BAENINGER, 1995; SALES, 1992 e 1995).

Como salientou Sales (1992), o trabaIhador brasileiro, nestes últimos 30 anos, tem, cada vez mais, participado desse processo de deslocamento que se caracteriza fortemente pela alienação física e social. Deve-se observar o resultado desse processo na constituição de projetos de deslocamento para terras estrangeiras, que se inserem em vias alternativas e marginais, tidos como única maneira de solucionar a miséria material e os conflitos sociais e simbólicos estabelecidos na vida comunitária do trabalhador.

Assim, atualmente, diversas estratégias de deslocamento foram desenvolvidas em função do novo contexto das relações internacionais e abriram caminho para a institucionalização de fluxos cada vez maiores de migrantes clandestinos. Em 16 estudos de caso internacionais analisados por Fazito (2005), as migrações internacionais que

\footnotetext{
6 Gostaria de agradecer a sugestão de um dos pareceristas para a leitura do estudo de Thomas Faist (2000) que, de fato, desenvolveu um trabalho pioneiro sobre as migrações e o papel desempenhado pelos agentes intermediários e as redes sociais.
} 
utilizam estratégias clandestinas, associadas às máfias do tráfico humano, têm se tornado práticas comuns entre os agentes da migração (SPAAN, 1994; SINGHANETRARENARD, 1992; SPENCER, 1992; CASTRO, 1998; EELENS; SPECKMANN, 1990).

No caso das emigrações internacionais brasileiras contemporâneas não é diferente. Como se verá a seguir, a emigração para os EUA segue amplamente esse padrão internacionalizado da clandestinidade, também responsável pelo reforço das posições estruturais de atravessadores (brokers) e das redes sociais da migração (familiares, amizade e de agenciadores) (FAZITO; SOARES, 2008).

\section{A rede migratória para os EUA e seus intermediários}

Os fluxos mais significativos da emigração internacional contemporânea no Brasil são, de fato, aqueles destinados à América do Norte, especialmente aos Estados Unidos. Embora não haja como identificar com precisão o destino das trajetórias dos emigrantes brasileiros, por meio das estimativas de imigração nos países de destino (como o caso de estimativas censitárias e amostrais nos EUA), é possível estabelecer algumas indicações sobre o volume e a intensidade dos deslocamentos.

Segundo estimativas do censo norteamericano de 1990, foram encontrados cerca de 95.000 brasileiros residentes nos EUA (MARTES, 2000:47), resultados esses conservadores, uma vez que não avaliaram a onda de imigrantes ilegais brasileiros iniciada em fins da década de 80 . No censo norte-americano publicado em 2000 , novos números indicam a dificuldade em precisar a quantidade de brasileiros imigrantes, mencionando-se no mínimo 160.000 e no máximo em 230.000 brasileiros legalizados nos EUA (MITCHELL, 2003:34).

Margolis (1994:42-3), baseando-se em dados do Bureau de Imigração dos EUA, pesquisas amostrais diversas, fontes da mídia impressa, associações comunitárias e religiosas e nos consulados brasileiros em território americano, expressa estimativas mais amplas, inclusive de imigrantes brasilei- ros ilegais (overstayers), citando entre $350 \mathrm{mi}$ e 400 mil em meados da década de 90.

Ao comparar os dados do censo norteamericano de 2000 com aqueles coletados pelo Ministério das Relações Exteriores do Brasil, Margolis (2003, p. 53) sugere que as estimativas oficiais norte-americanas são mesmo bastante conservadoras: enquanto o censo apontava cerca de 200.000 imigrantes brasileiros em solo americano, o Itamaraty contabilizava algo em torno de 800.000.

Seja como for, quando ponderados esses números com as estimativas mais recentes e confiáveis da emigração internacional brasileira nos últimos 20 anos (CARVALHO, 1996; CARVALHO et al., 2000; CARVALHO et al., 2001), verifica-se a preponderância dos deslocamentos de brasileiros para os EUA.

Segundo Carvalho et al. (2001, p. 249), "os emigrantes, que gravitavam ao redor de 1.038.000, no período 1986/1991, teriam atingido a marca de pouco mais de, no máximo, 1.114.000 pessoas no qüinqüênio seguinte". Embora a contagem do IBGE, em 1996, não tenha cobertura confiável, constatou-se que o Brasil deve ter perdido cerca de 1.800.000 pessoas em toda a década de 90, indicando a constância dos deslocamentos para o exterior do país e, até certo ponto, um aumento dos fluxos emigratórios.

Como mostram os diversos estudos da literatura especializada sobre as emigrações de brasileiros para os EUA nos últimos 20 anos, também existem singularidades na distribuição, organização e composição desses fluxos. Notadamente, a concentração de mineiros, paulistas, cariocas, goianos e, mais recentemente, catarinenses no contingente emigrante - além de a distribuição de sexos ter se tornado cada vez mais equilibrada - tem chamado a atenção dos pesquisadores da migração (SALES, 1995 e 1999; MARTES, 2000 e 2003; SOARES, 2002b; GOZA, 1992, 1994 e 2003; MARGOLIS, 1994 e 2003; MITCHELL, 2003; ASSIS, 2003; RIBEIRO, 1999).

Parece que a concentração de indivíduos conterrâneos, ou seja, procedentes do mesmo estado e, com freqüência, da mesma microrregião brasileira - como 
atestam os casos marcantes de valadarenses (SOARES, 2002b), goianos (RIBEIRO, 1999) e criciumenses (ASSIS, 2003) -, tanto nas partidas e chegadas, quanto nos trajetos e, principalmente, na fixação junto às comunidades imigrantes nos EUA, mostra intrinsecamente a preponderância ativa das redes sociais da migração (TILLY, 1990; MASSEY et al., 1987; SOARES, 2002a e 2003; FAZITO, 2002).

Desse modo, deve-se atentar para a participação dos mecanismos intermediários (agentes, atravessadores, recrutadores) nos projetos migratórios desses brasileiros que desejam viver nos EUA, pois cumprem papel decisivo na realização do trajeto físico e social do migrante. Dir-se-ia que não se migra simplesmente porque se deseja migrar. Para o deslocamento, qualquer indivíduo deve estar em condições estruturais, ou seja, ocupar uma posição estrutural no sistema que the possibilite migrar.

Especialmente a partir do início da década de 90 , quando as políticas de imigração norte-americanas tornaram-se mais rigorosas e o Bureau de Imigração dos EUA endureceu os critérios de entrada para brasileiros, as estratégias até então utilizadas pela maior parte dos emigrantes (basicamente através da obtenção de vistos de turista nos consulados americanos) tiveram que mudar de maneira radical. A imigração ilegal aumentou sensivelmente e, por conseqüência, as rotas da clandestinidade começaram a fazer parte das alternativas da maioria dos brasileiros que desejavam entrar nos EUA (MARGOLIS, 1994; SALES, 1999; FAZITO; SOARES, 2008).

Há grande recorrência nos relatos dos emigrantes brasileiros quanto às estratégias adotadas para entrada em território americano. Quando os vistos de turista são negados, muitas vezes depois de 3 ou 4 tentativas em diferentes consulados, os brasileiros procuram acionar suas redes pessoais em busca de alternativas mais sofisticadas: viagem clandestina em navios cargueiros; travessia com diversas escalas por vários países europeus ou latino-americanos; travessia em grupos pela fronteira do México, auxiliados por coiotes; falsificação de passaporte e outros documentos para facilitação do desembarque nos portos de entrada nos EUA (SALES, 1999, p.75 e ss.; SOARES, 2002; FAZITO; SOARES, 2008).

Desse modo, o sistema de emigração internacional para os Estados Unidos gerou uma verdadeira "indústria do deslocamento", que, alicerçada e alimentada pelas redes pessoais dos migrantes (inclusive retornados e imigrantes, semelhante ao caso das empresas dekasseguis no Japão), ampliouse paulatinamente e consolidou esquemas mais complexos e obscuros.

$\mathrm{Na}$ atualidade, muitos migrantes viajam por meio de agências de turismo especializadas na emigração clandestina, ou, ainda, utilizam agentes (brokers) conectados às redes de tráfico humano, falsificação de documentos e remessas ilegais de dinheiro. Muitas agências e agentes parecem, também, se conectar transnacionalmente a outras redes mafiosas de tráfico, como os business-coyotes mexicanos (CASTRO, 1998; SOARES, 2002b; SALES, 1999; GOZA, 2003).

Segundo Margolis (1994, p. 92),

os brasileiros pagam em torno de $5 \mathrm{mil}$ dólares por uma passagem aérea para a Cidade do México, pelo transporte até a fronteira, pela cobertura de um coiote para cruzá-la, pela viagem para uma cidade da fronteira americana, e por uma passagem aérea só de ida da cidade da fronteira até o destino final. Este era o custo real de uma viagem oferecida por uma agência de Governador Valadares àqueles que não conseguiam obter vistos de turista para os Estados Unidos.

Porém, como ressaltou Goza (2003), os emigrantes que utilizam essas rotas mais sofisticadas e caras são, via de regra, em sua maioria, indivíduos provenientes da classe média-baixa brasileira, em especial o caso dos valadarenses. É neste sentido que as redes sociais dos emigrantes tornam-se de grande importância, pois são responsáveis pelo apoio social e financeiro no momento da contratação dos serviços clandestinos das agências de turismo e seus brokers.

Sobre o caso específico dos valadarenses, Goza (2003, p. 275) afirma que

as agências também estavam quase sempre dispostas a trabalhar com aqueles que não tinham condições de pagar imediatamente 
por uma passagem internacional - com base no fato de que os parentes destes candidatos tinham recursos financeiros suficientes e estavam dispostos a reembolsar estas agências se o pagamento não fosse recebido no tempo certo. Freqüentemente, isso implicava pagar taxas de juros durante o período de empréstimo. Porém, algumas famílias faziam sacrifícios ainda maiores para permitirem que um de seus membros pudesse emigrar, e, ocasionalmente, vendiam veículos, terras, animais da fazenda, televisões e/ou geladeiras para financiar estas viagens. Para alguns emigrantes, a viagem teria sido completamente impossível se não tivessem sido capazes de receber esse apoio financeiro de suas famílias.

Nas cidades americanas com maior concentração de brasileiros, a presença de mineiros (especialmente valadarenses) e suas redes sociais é fato marcante. ${ }^{7}$ Focalizando a história recente da emigração na cidade de Governador Valadares, pode-se observar como as redes sociais no processo migratório funcionam como mecanismos poderosos de sustentação e consolidação dos fluxos, atestando as considerações de Massey et al. (1987).

Ao relacionar os fluxos de emigração internacional da microrregião valadarense com as evidências mais concretas das redes sociais dos emigrantes e agentes intermediários de Governador Valadares, Soares (2002b) mostra como a mobilização dos deslocamentos está fortemente condiciona$\mathrm{da}$ às estruturas reticulares.

Interessante notar que, ao final da década de 80 , as agências de turismo (e seus agentes) em Governador Valadares começaram a se tornar cada vez mais presentes no cotidiano da cidade e a tomar parte nas redes pessoais dos emigrantes. Além de intermediar emigrantes que não são capazes de conseguir o visto de turista (ou outro tipo de visto adequado à entrada nos EUA), as agências de turismo também passaram a ocupar o espaço de financeiras, falsificadoras de documentos e agenciadoras de remessa de moeda estrangeira (SOARES, 2002b; GOZA, 2003; MARGOLIS, 1994).

As agências e os agentes em Governador Valadares, diante da lucratividade da "indústria do deslocamento", cresceram seguindo passos semelhantes aos ativados pelos mecanismos intermediários (brokers) de outros sistemas migratórios internacionais (EELENS; BECKMANN, 1990; SINGHANETRA-RENARD, 1992; SPAAN, 1994). As agências ocuparam posições estruturais exclusivas no sistema da emigração internacional brasileira; pode-se dizer, uma ocupação necessária e inexorável. Tanto assim que, de maneira geral, esses mecanismos de intermediação sofisticados e bastante especializados emergiram, num momento relativamente posterior aos grandes fluxos de emigração, em regiões centrais do contexto migratório brasileiro.

Em outras palavras, a topologia específica desse sistema de migração leva os atores concretos (por exemplo, agências de turismo e agentes) a ocuparem determinadas posições latentes disponíveis. A partir do momento em que algum ator específico torna-se capaz de articular sua qualidade social concreta à força relativa da posição estrutural, esse intermediário passa a capitalizar maior poder em relação aos demais. Portanto, a ocupação das posições estruturais não depende apenas do "desejo" de determinados atores, pois é o efeito de uma convergência estrutural, em que outros atores são incapazes ou, pelo menos, não objetivam a ocupação de uma posição específica.

Percebe-se que, após a consolidação dos fluxos emigratórios em Governador Valadares, no final dos anos 80 , coincidentemente com a mudança da política imigratória em relação aos brasileiros e o conseqüente aumento da clandestinidade, a rede das agências de turismo, falsificação de documentos, remessas de dinheiro, agentes, atravessadores e coiotes expandiu-

\footnotetext{
7 Na pesquisa de Goza (1992), no Canadá e no norte dos Estados Unidos, cerca de $60 \%$ dos imigrantes eram mineiros, sendo $20 \%$ de toda a amostra composta por valadarenses. Na pesquisa de Margolis (1994), $41 \%$ eram mineiros; em Bicalho (1989), 89\% dos pesquisados eram mineiros, sendo 42\% provenientes de Governador Valadares; em Martes (2000), 17\% da amostra, a maior representação, constituía-se de valadarenses, $11 \%$ de belo-horizontinos e $6 \%$ de ipatinguenses.
} 
se e consolidou-se definitivamente, já em meados dos anos 90 (SOARES, 2002b).

Deve-se considerar, ainda, o reforço comunitário desses laços de clandestinidade a partir das redes pessoais dos migrantes, pois, como lembra Goza (2003, p. 274), em Governador Valadares, vários agentes e agências de turismo iniciaram seus negócios por meio de migrantes retornados, que perceberam no tráfico ilegal de pessoas, através da fronteira americana, um ótimo empreendimento comercial - aliás, como mostram diversos estudos de caso, há uma forte tendência empírica de migrantes retornados transformarem-se em poderosos agenciadores da emigração clandestina (cf. EELENS; BECKMANN, 1990; SINGHANETRA-RENARD, 1992; SPAAN, 1994; MARTIN, 1998; CASTRO, 1998; GOZA, 2003).

Como afirma Soares (2002b, p. 114),

a lucratividade 8 gerada por essa prática de intermediar tanto o fluxo de emigrantes internacionais quanto o de moeda estrangeira manifesta-se pelo progressivo aumento do número de agências de turismo em Valadares. A distribuição dessas agências de acordo com o surgimento no tempo (...) revela a coincidência entre o período em que se estabelece o maior número delas e o período em que a emigração foi mais intensa: $60 \%$ das agências surgiram entre 1985 e 1989, incluindo os extremos, e 43,6\% dos emigrantes saíram de Valadares nesse mesmo recorte temporal. Em 1991, Valadares, que abrigava cerca de 210 mil habitantes, contava com o total de 45 agências de turismo".

Já em março de 2003, em uma pesquisa com o banco de dados da Secretaria Municipal da Fazenda de Governador Valadares, contabilizou-se a existência de aproximadamente 70 agências de turismo em operação. ${ }^{9}$ Portanto, deve-se considerar a pertinência da atuação das agências de turismo (e seus esquemas reticulares) para a compreensão da estrutura do sistema de emigração brasileiro contemporâneo - pois, como tem sido noticiado pela imprensa brasileira nos últimos dois anos, segundo investigação da Polícia Federal, indícios sugerem que a rede ilegal das agências de Valadares se estende a outras cidades brasileiras, como Vitória, Rio de Janeiro e Poços de Caldas.

Além da intermediação das agências, outras estratégias de deslocamento, complementares ou não, têm sido demandadas pelos emigrantes brasileiros. Martes (1999 e 2000) estudou a presença das igrejas nas comunidades de imigrantes brasileiros na região de Boston, nos Estados Unidos. Segundo a autora, as igrejas, com destaque para as chamadas igrejas evangélicas, poderiam operar como recrutadoras e incentivadoras da emigração de brasileiros para os EUA, pois sua organização institucional, seguindo princípios expansionistas, exigiria a participação ativa e dinâmica de pastores e pregadores da fé (MARTES, 2000, p. 113).

Independente da existência ou consolidação desse canal de emigração, o fato importante é que, como mostra Martes (1999, p. 108), as igrejas brasileiras nos Estados Unidos fornecem apoio social aos imigrantes e oferecem uma espécie de "Iocalização" simbólica e concreta no destino, ao integrarem os imigrantes no "mundo do trabalho".

Por fim, embora não seja possível precisar os fluxos de emigrantes brasileiros pertencentes às classes média e alta, que se fixam nos Estados Unidos por meio de contratos de trabalho ou estudo (especificamente o que poderia ser identificado como uma forma de braindrain brasileiro), pode-se dizer que uma parcela, talvez minoritária (embora cada vez maior na última década), ${ }^{10}$ de emigrantes utiliza rotas mais tradicionais

\footnotetext{
8 Segundo Margolis (1994, p. 164), a "maior agência de remessa na cidade recebia quase 1 milhão de dólares por mês..."

9 Durante o segundo semestre de 2003, com o auxílio de Weber Soares, tivemos a oportunidade de selecionar e compilar os registros jurídicos das agências de turismo de Governador Valadares, presentes na Secretaria Municipal da Fazenda, que contabilizavam o ano de fundação da empresa e o volume da contribuição financeira (ISS) prestada ano a ano. Foram investigadas todas as agências cadastradas oficialmente, entre 1975 e março de 2003, totalizando 128 agências supostamente em operação. No entanto, soube-se que muitas das agências já não mais existiam ou tinham se tornado clandestinas, além do mercado empresarial exibir elevada rotatividade. De todo modo, cerca de 70 agências de turismo operavam legalmente na cidade em março de 2003.
} 
e legalizadas de deslocamento. Contudo, mesmo nessas estratégias, encontram-se as redes pessoais em ação.

Portanto, ao sintetizar as posições estruturais estabelecidas nesse complexo sistema de migração internacional, encontraremos as redes pessoais (baseadas nos laços familiares e de amizade) ocupando espaços fundamentais da intermediação assim como podem também ser observadas em outros sistemas migratórios, especialmente entre os dekasseguis (cf. FAZITO, 2005, cap. 5).

\section{Análise do modelo estrutural da emigração de brasileiros para os EUA}

A partir da revisão da literatura especializada sobre as migrações de brasileiros para os EUA, realizou-se a configuração de um sistema de migração internacional. Deve-se deixar claro que o sistema migratório reconstituído é um modelo de referência baseado nos dados empíricos coligidos pela literatura consultada. As posições estruturais foram determinadas tendo como base os trajetos percorridos pelos migrantes brasileiros para chegarem aos EUA. Em síntese, elas podem ser enumeradas como: 1. emigrantes; 2. familiares e amigos (no Brasil); 3. familiares e amigos (nos EUA); 4. agentes independentes (recrutadores/brokers); 5. agências de turismo; 6. falsificadores (brokers para documentos); 7. retornados; 8. igrejas (na comunidade de imigrantes); 9. pastores; 10. coiotes (mexicanos). Aqui, assume-se, por hipótese, que essas dez posições estruturais seriam suficientes para descrever os aspectos topológicos desse sistema de migração.

Seguindo linhas gerais na interpretação das informações contidas nos estudos analisados até aqui, pode-se dizer que o emigrante seria capaz de seguir três estratégias alternativas de deslocamento (que podem ser visualizadas no sociograma da Figura 1):
1. se o emigrante conseguisse $o$ visto de turista imediatamente, então seria capaz de viajar, entrar e fixar-se em território americano, necessitando apenas contatar a agência de turismo na saída do Brasil e os familiares ou amigos no destino;

2. se o emigrante não fosse capaz de adquirir o visto de turista, poderia lançar mão de sua rede pessoal no Brasil (familiares e amigos) e, posteriormente (ou, de imediato, mesmo sem contatos pessoais), optar pelo suporte de um agente independente (recrutador especializado ou retornado que deve, necessariamente, fazer parte do círculo social do emigrante), que, por sua vez, caso necessário, acionaria o agente da falsificação, a agência de turismo e, finalmente, colocaria o emigrante em contato com sua rede pessoal no destino - nessa alternativa deve-se considerar ainda a possibilidade de entrada via fronteira mexicana, onde o coiote de fronteira seria acionado pelos agentes brasileiros;

3. o emigrante poderia utilizar a rota instituída pelas igrejas da comunidade imigrante, acionando um pastor evangélico, seja de imediato, seja através dos laços de sua rede pessoal. O pastor poderia acionar sua rede pessoal e profissional, utilizaria a intermediação das agências de turismo (ou mesmo de agentes especializados, caso não obtivesse visto oficial) para a travessia e, finalmente, no destino, colocaria o emigrante em contato com a igreja da comunidade - ainda, nesse caso, o imigrante, junto de sua rede pessoal no destino, poderia entrar em contato com a igreja.

\footnotetext{
10 Por exemplo, dados do Departament of Homeland Security, dos EUA, mostram um pequeno crescimento da legalização de brasileiros que possuem capital humano elevado (especialmente educação superior - cf. http://www.dhs.gov/ximgtn/ statistics/publications/yearbook.shtm). Certamente, o braindrain brasileiro merece estudos mais profundos e detalhados para subsídio de políticas públicas eficazes. Os autores gostariam de agradecer especialmente a um dos pareceristas da Rebep pela indicação destas informações sobre o braindrain de brasileiros nos EUA.
} 
Essas três estratégias, de fato, baseiam-se em casos reais diversos de pessoas que decidem pela migração para os EUA. Por exemplo, a primeira, em geral, é utilizada por pessoas que possuem maior capital humano e conseguem facilmente um visto de entrada para os EUA. Entram como turistas, estudantes ou trabalhadores temporários e, através de suas redes pessoais, são capazes, posteriormente, de se estabelecerem definitivamente, seja regular ou irregularmente. A segunda estratégia é basicamente utilizada por migrantes que têm o visto negado e tentam a trajetória clandestina (de fato, a formalização desta estratégia foi feita a partir dos relatos de migrantes brasileiros irregulares na região de Governador Valadares). E a terceira está ligada particularmente à estrutura das organizações religiosas estabelecidas no Brasil e EUA, segundo uma lógica transnacional (MARTES, 1999).

A seguir, são analisadas as propriedades formais do sociograma, que corresponde apenas à visualização de uma rede ou sistema (neste caso, um sistema típico-ideal das migrações internacionais de brasileiros para os EUA), que pode se fundamentar numa lógica matemática dos algoritmos utilizados para sua representação. Aqui, a análise do sociograma foi baseada em algumas medidas da Análise de Redes Sociais (densidade, coesão, centralidade e intermediação), que, estudadas em conjunto, identificam a disposição estrutural dos laços e pontos em uma rede, ou seja, o padrão estrutural de distribuição dos parâmetros fundamentais.

A medida de densidade informa a proporção de "laços efetivos" entre "laços possíveis". Quanto mais próxima de 1, mais densa será a rede. A densidade é uma medida fundamental, pois indica a variação da distribuição de pontos e laços num sistema de relações. Quanto mais densa (próxima de 1), mais uniforme será o padrão de contatos entre os pontos (atores) de um sistema. Uma densidade baixa (inferior a 0,2, cf. Wasserman e Faust, 1994, cap.4) indica uma rede dispersa e com baixa coesão interna, com proeminência de posições isoladas e baixo poder de "arregimentação". Um sistema migratório com baixa densidade exibiria uma tendência elevada para o deslocamento irregular controlado por agenciadores mais isolados.

A medida de coesão baseia-se na ponderação das distâncias internas da rede, isto é, o número de passos efetivos (laços necessários para conectar duas posições ou atores) entre cada par de atores da rede. Sistemas com distâncias elevadas sugerem fraca coesão interna e maior isolamento das posições/atores. A medida de coesão próxima de 1 indica um sistema extremamente integrado, em que todos estão ligados diretamente a todos os outros. Contudo, as redes empíricas dificilmente mostram uma coesão acima de 0,5 e, em geral, os sistemas apresentam uma coesão média, em torno de 0,3 (WASSERMAN; FAUST, 1994, cap. 4).

Para o sistema de migração aqui estudado, encontrou-se uma densidade média de 0,24 e coesão relativamente alta de 0,32, ou seja, uma densidade baixa para média e uma coesão média. Em linhas gerais, esses dois algoritmos indicam um sistema pouco homogêneo e bastante esparso, em que os indivíduos e suas posições permanecem isolados da maior parte dos outros. De certo modo, segundo uma perspectiva relacional, esse fato evidencia a dependência nas relações entre determinadas posições, bem como o fortalecimento daquelas posições/ indivíduos que se localizam mais isolados, mas capazes de conectar grupos de posições diversas - por exemplo, o caso dos agentes que conhecem coiotes mexicanos na fronteira com os EUA.

Mesmo que a densidade e coesão da rede, em princípio, favoreçam estruturalmente alguma posição para intermediação dos migrantes (especialmente as posições ocupadas pelas famílias e amigos, e retornados), verifica-se um padrão de intermediação disperso, pouco concentrado formalmente.

Por conseqüência, o sistema parece mesmo ser mais difuso e esparso, com baixa tendência à aglomeração em torno das posições e maior heterogeneidade quanto à distribuição da força dos inter- 


\section{FIGURA 1}

Modelo estrutural do sistema de emigração brasileira para os Estados Unidos
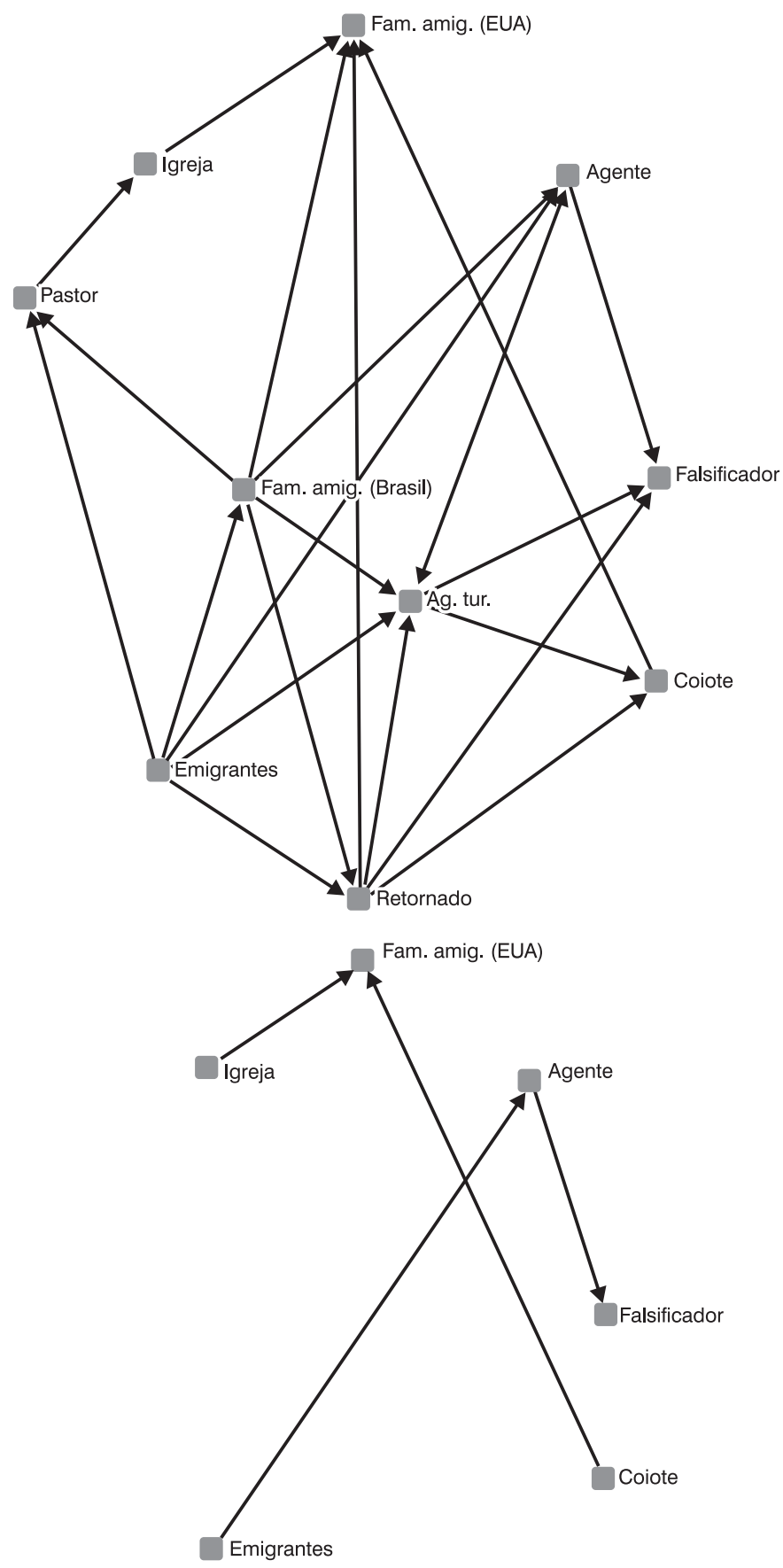

Fonte: Dados pesquisados e organizados por Fazito (2005). 
mediários, isto é, diversos intermediários se alternam na exploração dos fluxos de emigrantes. ${ }^{11}$

A relação entre as posições estruturais garante aos atores, na prática, a possibilidade de se conectarem facilmente e de forma estável. Nesse sentido, o sistema pode se tornar mais dinâmico, flexível e ativo, pois os atores (emigrantes, intermediários e receptores) podem utilizar diversas estratégias (de conexão) ao mesmo tempo. Contudo, devese ter em mente que esta é uma possibilidade formal, dada a topologia do sistema. Pode-se dizer, portanto, que a ocupação de uma determinada posição estrutural "facilita" ou "limita" a ação concreta de determinado ator na rede social da migração.

$\mathrm{Na}$ análise estrutural das posições intermediárias desse sistema, verifica-se uma proeminência relativa da posição ocupada pelas agências de turismo. Embora o sistema de intermediação seja mais difuso e esparso, gerando instabilidade e competição mais acirrada entre os diversos atores em suas posições, os resultados encontrados pelos algoritmos de rede indicam sistematicamente as agências de turismo como ocupantes da posição mais privilegiada (formalmente) para a intermediação.

Para isso foram utilizadas aqui as medidas de centralidade e intermediação, que indicam o "grau de atividade" de uma rede, ou seja, a capacidade de atores/posições se conectarem direta ou indiretamente a outros. Quanto mais próximo de $100 \%$, mais centralizado será um sistema, mostrando variação estrutural extrema. O algoritmo dessa medida baseia-se em um modelo geométrico da "rede-estrela", que indica justamente a variação extrema, ou seja, uma posição central (A) e outras quatro posições $(B, C, D, E$,$) periféricas ligadas diretamente$ e apenas à $A$. Nesse caso, A tem um índice de $100 \%$ e toda a rede converge para essa posição, enquanto as demais posições estão no outro extremo, com uma centralidade de $25 \%$ (se conectam diretamente apenas a uma entre quatro posições possíveis). A medida de intermediação deriva do mesmo algoritmo e considera não a relação direta entre as posições, mas sim a capacidade de uma posição A "colocar em contato" posições não ligadas diretamente.

A análise do grau de centralidade mostra que as agências, seguidas pelos retornados e agentes recrutadores, concentram os fluxos das relações com os emigrantes. Quando comparados os valores de intermediação de fluxos (grau de centralidade de intermediação), ${ }^{12}$ mais uma vez as agências sobressaem com um grau de intermediação acima das demais posições (7\%).

Embora esse sistema de migração não apresente posições estruturais formalmente privilegiadas (aqui chamados vértices-obstáculo ideais), ${ }^{13}$ pode-se dizer que, a partir da convergência entre a força estrutural presente em uma posição de intermediação e a ação concreta exercida por determinado ator, as agências de turismo são os atores empíricos mais efetivos na intermediação dos emigrantes, pois, além de serem formalmente os mais proeminentes (como mostrado na análise anterior - maiores índices de centralidade e intermediação), empiricamente concentram volume de contato e têm grande visibilidade entre os migrantes potenciais (como pode ser constatado em trabalhos de campo em Governador Valadares e Poços de Caldas).

Assim, as agências de turismo deveriam ser entendidas apenas como atores concretos mais bem sucedidos na combinação de posições estruturais de intermediação ocupadas e ação prática efetiva no "repasse" de pessoas.

\footnotetext{
${ }^{11}$ A medida de centralidade de intermediação de apenas $6 \%$ indica que não existe uma posição intermediária dominante ou monopolizadora dos fluxos. Quanto mais próxima de 100\%, mais centralizada sobre uma posição estrutural ou ator seria a rede, ou seja, uma posição monopolizaria todos os fluxos de migrantes (WASSERMAN; FAUST, 1994).

12 Para cada posição isolada, derivou-se uma medida conhecida como "intermediação de fluxos", que indica o monopólio dos laços das redes ponderados pela centralidade de intermediação da rede total. Assim, tem-se uma medida que avalia a força relativa de intermediação de cada ator/posição na rede analisada (cf. BORGATTI et al. 2002).

13 Os vértices-obstáculo ideais (cutpoints) são posições estruturais capazes, formalmente e, por extensão, empiricamente, de desconectar um grafo/rede social. Se determinada posição for "excluída" de uma rede social, então ela se desconecta, afetando radicalmente sua topologia (cf. WASSERMAN; FAUST, 1994).
} 
Ao se analisar o sociograma por meio da simulação dos vértices-obstáculo e blocos estruturais (quadro inferior da Figura 1), verifica-se que, nesse sistema, a composição das posições estruturais ocupadas pelas agências de turismo, pelo pastor, pelos retornados e pela rede familiar e de amizade de brasileiros em uma unidade corresponderia a um bloco de intermediação do sistema, isolando origem e destino. É preciso notar que a posição dos agentes, coiotes e falsificadores depende das agências de turismo, enquanto as redes familiares e de amizade no Brasil e nos EUA também dependem das posições intermediárias ocupadas por pastores, retornados e agências - fato que reforça a posição de intermediação ocupada pelas agências de turismo.

Nesse sentido, seria possível acreditar que o poder de intermediação, mesmo que formalmente limitado, concentra-se primeiro nas mãos das agências de turismo, seguidas pelos pastores (na realidade, um "poder local" nesse sistema, visto que está restrito aos imigrantes adeptos de uma "Igreja" particular) e pelos retornados brasileiros (brokers capazes de competir mais acirradamente com as agências de turismo - fenômeno que se confirma e se reforça através dos relatos sobre retornados, que montam suas próprias agências em Governador Valadares - ver Goza, 2003).

\section{Considerações finais}

Como procurou-se mostrar até aqui, a posição de intermediação no sistema de emigração para os EUA, assim como todos os sistemas de migração em geral, deve ser uma prerrogativa formal relativa que, em larga medida, independe dos processos empíricos de migração (FAZITO, 2005). Em outras palavras, a combinação ou sobreposição do sistema empírico com suas relações de ordem formal pode ocorrer ou não. Porém, se tal sobreposição ocorre, então ela indica atores posicionados mais vantajosamente do que outros e, nesse sentido, empiricamente mais poderosos e monopolistas dos fluxos do que outros.

Portanto, a análise estrutural poderá mostrar que, mesmo se não existissem agências de turismo capazes de ocupar com sucesso a posição de intermediação nesse sistema de migração, cedo ou tarde outros atores conquistariam esse espaço - dados os constrangimentos formais da estrutura reticular (SOARES, 2002a; FAZITO, 2005).

No caso das agências, sua preponderância efetiva parece emergir de uma coincidência estrutural e empírica no curso histórico dos deslocamentos brasileiros: elevação da demanda emigratória a partir de meados da década de 80; intensificação da política de imigração norte-americana favorecendo a clandestinidade das trajetórias; e consolidação das redes sociais dos emigrantes (especialmente os primeiros retornados, que se tornaram empresários das agências de turismo).

Porém, é ainda necessário promover a coleta de dados empíricos que dêem maior suporte às possibilidades teoricamente aventadas neste trabalho. Isto é, parece-nos necessário comprovar a análise exploratória aqui esboçada através de uma nova abordagem que dê conta dos microfundamentos das redes sociais da migração - este trabalho concentrou-se basicamente na dimensão macroestrutural das relações entre posições estruturais de um sistema empírico de migração, e ganharia mais com a agregação da dimensão microestrutural.

Finalmente, reforça-se que esta tentativa de análise estrutural pode ser uma alternativa promissora, mas que ainda merece maiores investimentos. Contudo, a descrição do sistema de emigração de brasileiros para os EUA, por meio da análise exploratória, sugere que as agências de turismo possam exercer, de fato (mais que formalmente), uma posição de intermediação dominante - especialmente reforçada pela disposição estrutural geral mais fraca das outras posições relativas do sistema. Em outras palavras, a força das agências, somada ao reflexo da debilidade dos outros intermediários e atores do sistema, pode tornar mais efetivo o constrangimento formal associado a uma posição ocupada concretamente; e isso parece ser uma importante observação, necessária à melhor compreensão dos fluxos de emigrantes para os EUA. 


\section{Referências bibliográficas}

ASSIS, G. De Criciúma para o mundo: os novos fluxos da população brasileira: gênero e rearranjos familiares. In: MARTES, A. C. B.; FLEISCHER, S. (Orgs.). Fronteiras cruzadas: etnicidade, gênero e redes sociais. São Paulo: Paz e Terra, 2003, p. 199-230.

BARABÁSI, A.-L. Linked - how everything is connected to everything else and what is means for business, science and everyday life. New York: Plume Book, 2003.

BICALHO, J. V. Yes, eu sou brazuca. Governador Valadares: Ibituruna, 1989.

BORGATTI, S. et al. Ucinet for Windows: software for social network analysis and user's guide. Harvard, MA: Analytic Technologies, 2002.

BOYD, M. Family and personal networks in international migration: recent developments and new agendas. International Migration Review, v.23, n.3, p.638-670, 1989.

BRIGANTI, L. Percorsi di toscani in Brasile tra '800 e '900: stati di Rio de Janeiro, Minas Gerais ed Espírito Santo. In: DAL PIEMONTE ALLO STATS DI ESPIRITO SANTO: ASPETTI DELLA EMIGRAZIONE ITALIANA IN BRASILE TRA OTTOCENTO E NOVECENTO; SEMINARIO INTERNAZIONALE, 1995, Torino, Itália. Atti del seminario internazionale. Torino: Centro Stampa della Giunta Regionale, 1996, p.259-285.

BRITO, F. Ensaio sobre as migrações internacionais no desenvolvimento do capitalismo. Revista Brasileira de Estudos de População, v.12, n1/2, p.21-33, 1995.

CARVALHO, J. A. M. de. O saldo dos fluxos migratórios internacionais do Brasil na década de 80: uma tentativa de estimação. Revista Brasileira de Estudos de População, v.13, n.1, p.3-14, jan./jun. 1996.

CARVALHO, J. A. M. de et al. Estimativas dos saldos migratórios internacionais e do número de emigrantes internacionais das grandes regiões do Brasil - 1986/1991 e 1991/1996. In: CASTRO, M. G. Migrações internacionais: contribuições para políticas. Brasília: CNPD, 2001, p.243-252.

CARVAlHO, J. A. M. de et al. Sinuosos caminhos para estimação do emigrantes internacionais de 1986/1991 e de 1991/1996 e saldos migratórios dos qüinqüênios entre 1981 e 1996 das Unidades da Federação Brasileira. In: ENCONTRO NACIONAL DE ESTUDOS POPULACIONAIS, 12., 2000, Caxambu. Brasil $\mathbf{5 0 0}$ anos: mudanças e continuidades. Campinas: Abep, 2000. (Disponível em CD-ROM).

CASTLES, S.; MILLER, M. J. The age of migration - international population movements in the modern world. 3a $\mathrm{ed}$. Londres: The Guilford Press, 2003.

CASTRO, G. L. Coyotes and alien smuggling. Migration between Mexico and the United States: binational study. Mexico City: Mexican Ministry of Foreign Afairs, v. 3, 1998, p.965-974.

DEGENNE, A.; FORSÉ, M. Introducing social networks. London Sage, 1999.

DIESTEL, R. Graph theory. $2^{\text {a. ed. New }}$ York: Springer-Verlag, 2000.

EELENS, F.; SPECKMANN, J.D. Recruitment of labor migrants in the middle east. International Migration Review, v.24, n.90, p.297-322, 1990.

FAIST, T. The volume and dynamics of international migration and transnational social spaces. Oxford, UK: Clarendon Press, 2000.

FAWCETT, J. Networks, linkages and migration systems. International Migration Review, v.23, n.3, p.671-680, 1989.

FAZITO, D. A análise de redes sociais (ARS) e a migração: mito e realidade. In: ENCONTRO NACIONAL DE ESTUDOS POPULACIONAIS, 13, 2002, Ouro Preto, $M G$. Violências, o estado e a qualidade de vida da população brasileira: anais. Belo Horizonte: Abep, 2002 (Disponível em CD-ROM).

Reflexões sobre os sistemas de migração internacional: proposta para uma análise estrutural dos mecanismos intermedi- 
ários. Tese (Doutorado em Demografia) - Belo Horizonte: Centro de Desenvolvimento e Planejamento Regional, Universidade Federal de Minas Gerais, 2005.

FAZITO, D.; SOARES, W. Undocumented migration, brokerage and solidarity: an exploratory network analysis of the BrazilUS migration system. In: POPULATION AMERICAN ASSOCIATION CONGRESS, New Orleans, USA, 17-20 April, 2008.

FIGOLI, L.; FAZITO, D. Redes sociales en una investigación de migración indígena: el caso de Manaus. In: ENCONTRO NACIONAL DE ESTUDOS POPULACIONAIS, 15. Caxambu, MG, 2006.

GORBATOV, V. A. Fundamentos de la matemática discreta. Moscou: Mir, 1988.

GOSS, J.; LINDQUIST, B. Conceptualizing international labor migration. International Migration Review, 29 (2):317-351, 1995.

GOZA, F. Brazilian immigration to North America. International Migration Review, v.28, n.1, p.136-152, 1994.

A imigração brasileira na América do Norte. Revista Brasileira de Estudos de População, v.9, n.1, p.65-81, 1992.

. Redes sociais e a integração de brasileiros no Canadá e nos Estados Unidos. In: MARTES, A. C. B.; FLEISCHER, S. (Orgs.). Fronteiras cruzadas: etnicidade, gênero e redes sociais. São Paulo: Paz e Terra, 2003, p.263-288.

HARARY, F. Graph theory. Reading, MA: Addinson-Wesley, 1969.

HARARY F.; WHITE, D. R. P-Systems: a structural model for kinship studies. Connections , v.24, n.2, p.35-46, 2001.

HUTTER, L. Imigração italiana em São Paulo (1880-1889): os primeiros contatos do imigrante com o Brasil. São Paulo: Universidade de São Paulo, Instituto de Estudos Brasileiros, 1972.

KNOKE, D.; KUKLINSKY, J. Network analysis. London SAGE, 1983.

KRISSMAN, F. Sin coyote ni patron: why the "migrant network" fails to explain international migration. International Migration Review, 39(1):4-44, 2005.

KRITZ, M. et al. (Eds.). International migration systems, a global approach. Oxford: Clarendon, 1992.

KRITZ, M.; ZLOTNIK, H. Global interactions: migration systems, processes and policies. In: KRITZ, M. et al. (Eds.). International migration systems, a global approach. Oxford: Clarendon, 1992, p.1-16.

MANBER, U. Introduction to algorithms: a creative approach. Reading MA, AddisonWesley, 1989.

MARGOLIS, M. Little Brazil: imigrantes brasileiros em Nova York. Campinas: Papirus, 1994.

. Na virada do milênio: a emigração brasileira para os Estados Unidos. In: MARTES, A. C. B.; FLEISCHER, S. (Orgs.). Fronteiras cruzadas: etnicidade, gênero e redes sociais. São Paulo: Paz e Terra, 2003, p.51-72.

MARTES, A. C. B. Brasileiros nos Estados Unidos: um estudo sobre os imigrantes em Massachussetts. São Paulo: Paz e Terra, 2000.

Os imigrantes brasileiros e as igrejas em Massachusetts. In: REIS, R. R.; SALES, T. (Orgs.). Cenas do Brasil migrante. São Paulo: Boitempo, 1999, p.87-122.

MARTES, A. C. B.; FLEISCHER, S. (Orgs.). Fronteiras cruzadas: etnicidade, gênero e redes sociais. São Paulo: Paz e Terra, 2003.

MARTIN, P. Guest workers: past and present. Migration between Mexico and the United States: binational study. Mexico City: Mexican Ministry of Foreign Afairs, v.3, 1998, p.877-895.

MASSEY, D. et al. Return to Aztlan, the social process of international migration from Western Mexico. Berkeley: University of California, 1987.

MASSEY, D. et al. Worlds in motion, understanding international migration at the 
end of the millennium. Oxford: Clarendon, 1998.

McCARTY, C. Structure in personal networks. Journal of Social Structure (edição online). Acesso em 2002.

MITCHELL, C. Perspectiva comparada sobre transnacionalismo entre imigrantes brasileiros nos Estados Unidos. In: MARTES, A. C. B.; FLEISCHER, S. (Orgs.). Fronteiras cruzadas: etnicidade, gênero e redes sociais. São Paulo: Paz e Terra, 2003, p.3350.

NEWMAN, M. E. J. The structure and function of complex networks. Society for Industrial and Applied Mathematics Review, 45(2):167-256, 2003.

ORE, O. Graphs and their uses. New York: Mathematical Assoc. of America, 1963.

PATARRA, N.; BAENINGER, R. Migrações internacionais recentes: o caso do Brasil. In: PATARRA, N. (Coord.). Emigração e imigração internacionais no Brasil contemporâneo. São Paulo: Fundo de População das Nações Unidas, 1995, p.78-88.

PORTES, A. Economic sociology and the sociology of immigration: a conceptual overview. In: PORTES, A. (Ed.). The economic sociology of immigration. New York: Russell Sage Foundation, 1995, p.1-41.

RIBEIRO, G. L. O que faz o Brasil: jogos identitários em São Francisco. In: REIS, R. R.; SALES, T. (Orgs.). Cenas do Brasil migrante. São Paulo: Boitempo, 1999, p.45-85.

SALES, T. Brasileiros longe de casa. São Paulo: Cortez, 1999.

O trabalhador brasileiro no contexto das novas migrações internacionais. In: PATARRA, N. (Coord.). Emigração e imigração internacionais no Brasil contemporâneo. São Paulo: Fundo de População das Nações Unidas, 1995, p.89-103.

Imigrantes estrangeiros, imigrantes brasileiros: uma revisão bibliográfica e algumas anotações para pesquisa. Revista
Brasileira de Estudos de População, v.9, n.1, p.50-63, 1992.

SASSEN, S. Immigration and local labor markets. In: PORTES, A. (Ed.). The economic sociology of immigration. New York: Russell Sage Foundation, 1995, p.87-127.

SCOTT, J. Social network analysis, a handbook. London: SAGE, 2000.

SINGHANETRA-RENARD, A. The mobilization of labour migrants in Thailand: personal links and facilitating networks. In: KRITZ, M. et al. (Ed.). International migration systems, a global approach. Oxford: Clarendon, 1992, p.190-204.

SOARES, W. Para além da concepção metafórica de redes sociais: fundamentos teóricos da circunscrição topológica da migração internacional. In: ENCONTRO NACIONALDE ESTUDOS POPULACIONAIS, 12, 2000, Caxambu. Brasil 500 anos: mudanças e continuidades. Campinas: Abep, 2002a (Disponível em CD-ROM).

Da metáfora à substância: redes sociais, redes migratórias e migração nacional e internacional em Valadares e Ipatinga. Tese (Doutorado em Demografia). Belo Horizonte, Centro de Desenvolvimento e Planejamento Regional, Universidade Federal de Minas Gerais, 2002b.

SPAANS, E. Taikongs and Calos: the role of middlemen and borkers in javanese international migration. International Migration Review, v.28, n.1, p. 93-113, 1994.

SPENCER, S. A. Illegal migrant laborers in Japan. International Migration Review, v.26, n.3, p. 754-86, 1992.

WASSERMAN, S.; FAUST, K. Social network analysis: methods and applications. Cambridge: Cambridge University, 1994.

WATTS, D. Small worlds: the dynamics of networks between order and randomness. Princeton: Princeton University, 2004.

WELLMAN, B. Structural analysis: from method and metaphor to theory and substance. In: SCOTT, J. (Ed.). Social networks: critical concepts in sociology. New York: Routledge, v. 1, 2002, p.81-122. 


\section{Resumen}

Emigración internacional de brasileños a los Estados Unidos: las redes sociales y el papel de intermediación en los desplazamientos, ejercido por las agencias de turismo

Este trabajo tiene como objetivo principal describir el papel de los "mecanismos intermediarios" (en especial el papel activo de las agencias de turismo) en el proceso de emigración internacional de brasileños a los EEUU. Al proponer una perspectiva relacional para el entendimiento del fenómeno migratorio, se procedió a un análisis estructural formal (fundamentado en el Análisis de Redes Sociales y Teoría de los Grafos) que posibilitase la comprensión de la emigración por medio de sus propiedades estructurales básicas. Las agencias de turismo ocupan una importante posición estructural de intermediación de las travesías de los emigrantes, desempeñando un papel preponderante en la regulación de los flujos migratorios a través de las redes sociales establecidas en el sistema de la migración internacional brasileña.

Palabras-clave: Emigración internacional. Redes sociales. Intermediación. Análisis estructural. Agencias de turismo. Modelo de Grafos.

\section{Abstract \\ International emigration of Brazilians to the United States: social networks and the role of mediation exercised by tourist agencies}

This article analyzes the role of "intermediary mechanisms" (especially the active role of tourist agencies) in the international emigration process of Brazilians to the USA. First a dynamic and relational approach to the understanding of the migration phenomenon is established. Next, a formal structural analysis (grounded on Social Network Analysis and Graph Theory) was carried out to facilitate understanding of emigration by considering its basic structural characteristics. The final analysis suggests that tourist agencies play an important role of structural mediation for migrants entering the country. The action of such agencies is decisive in regulating migratory flows through well-established social networks in the Brazilian international migration system.

Keywords: International emigration. Social networks. Mediation. Structural analysis. Tourist agencies. 